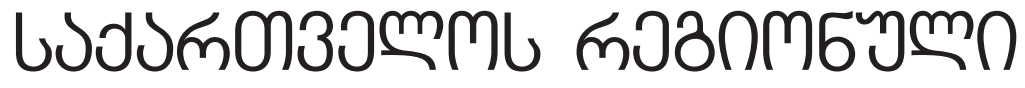

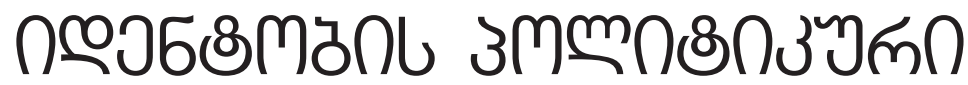

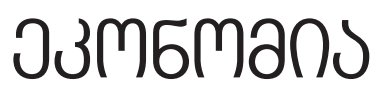

https://doi.org/10.35945/gb.2016.01.006

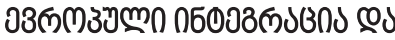

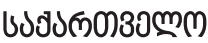

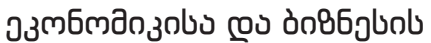

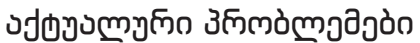
амmòmo8

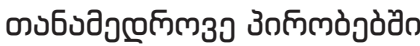

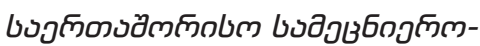

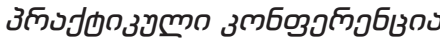

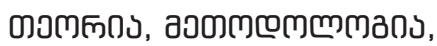

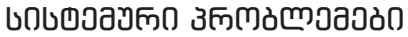

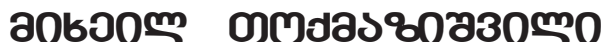

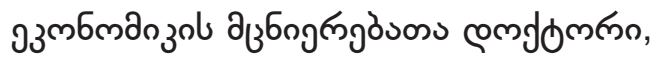

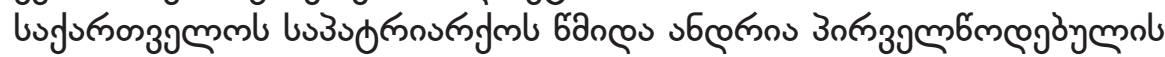

lubgmmàl jumon

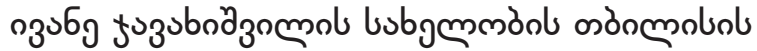

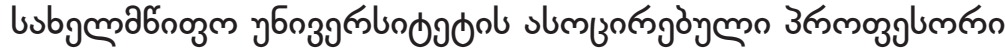

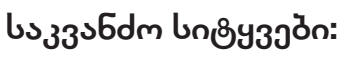

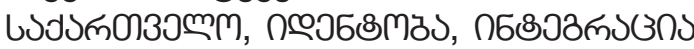

\section{əou১3১mก}

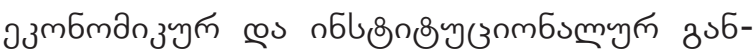

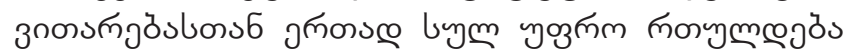

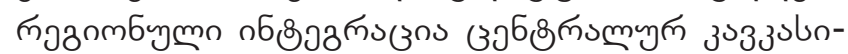

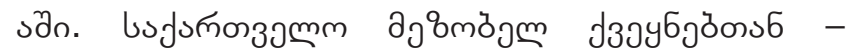

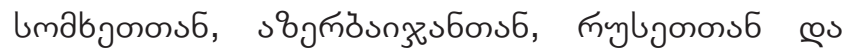

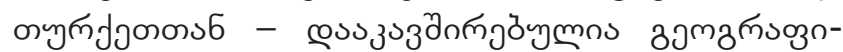

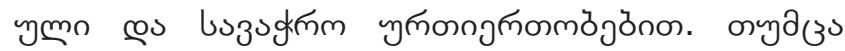

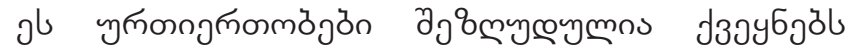

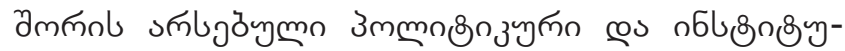

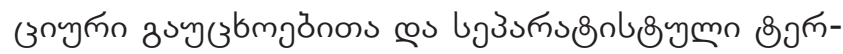

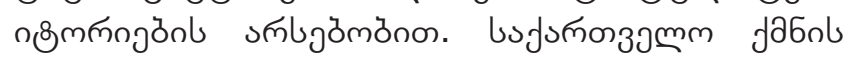

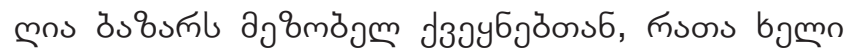

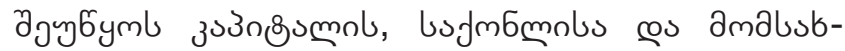

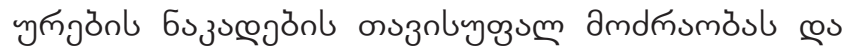

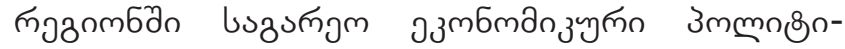

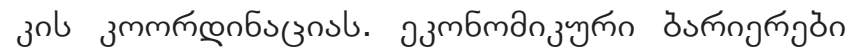

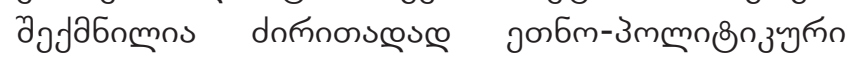

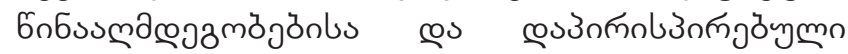

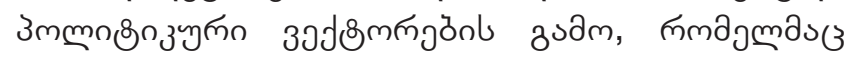

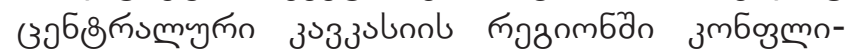

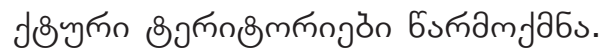

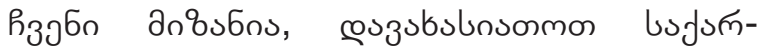

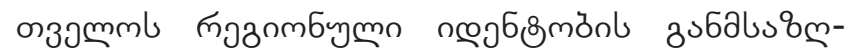
3

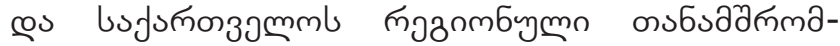

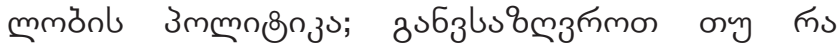

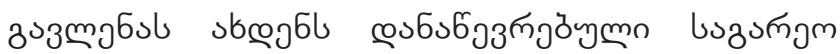

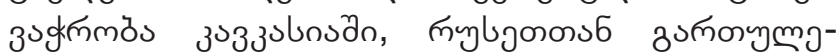

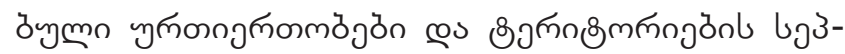

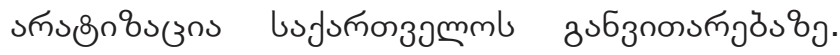

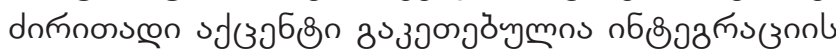

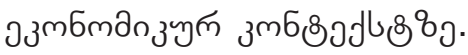

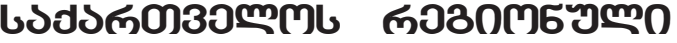

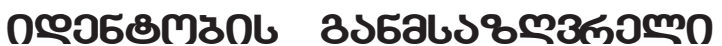

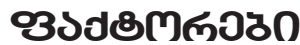

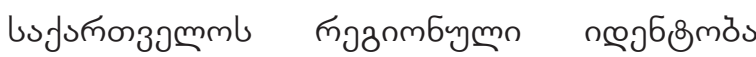

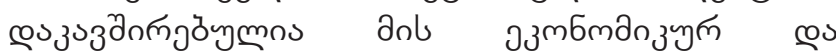

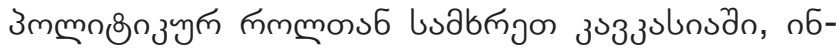

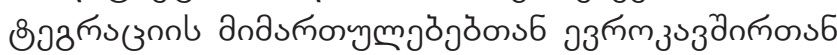

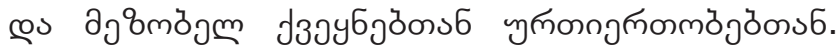

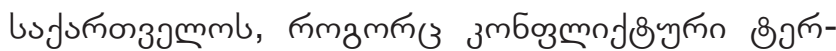

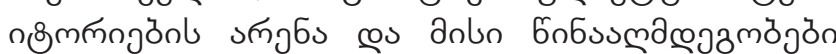

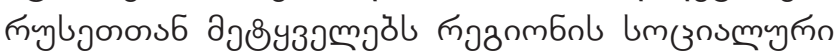

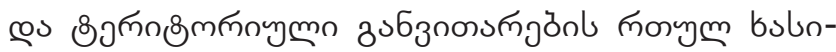

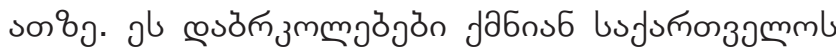

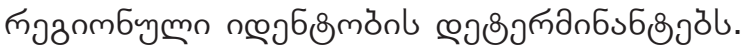

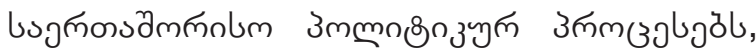




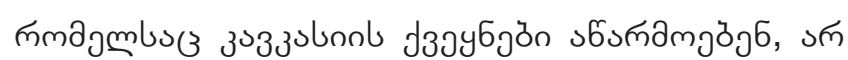

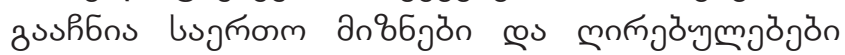

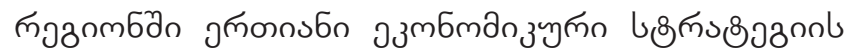

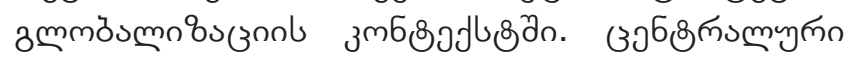

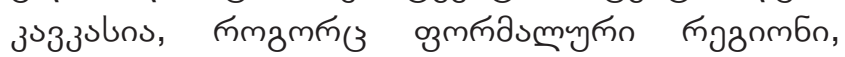

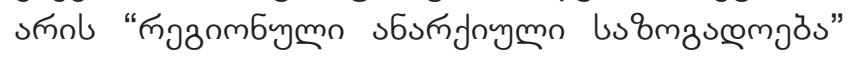

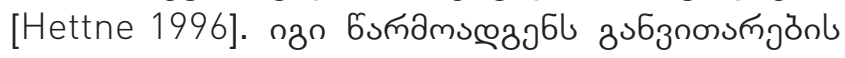

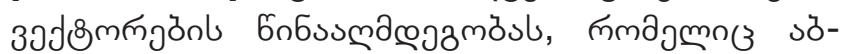

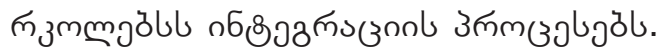

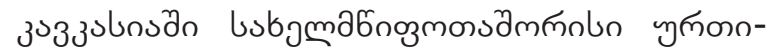

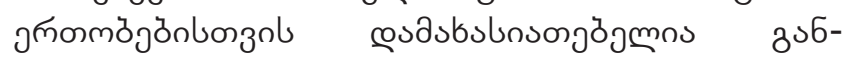

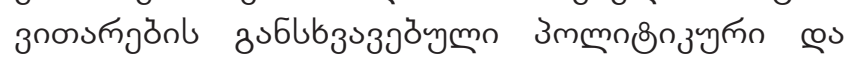

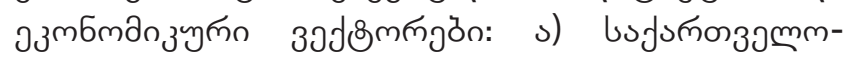

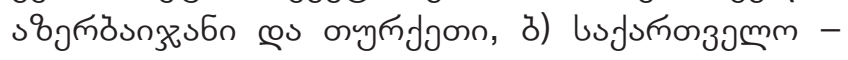

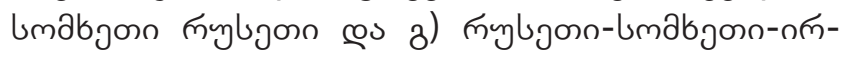

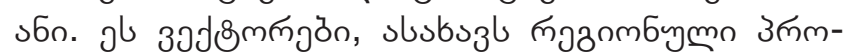

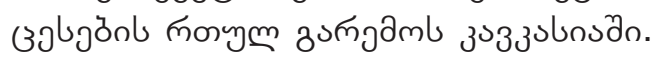

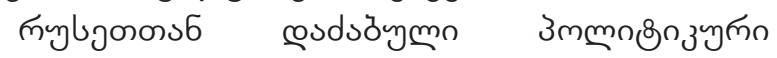

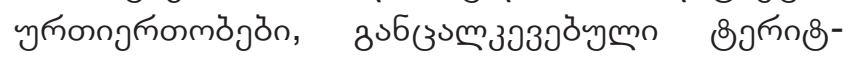

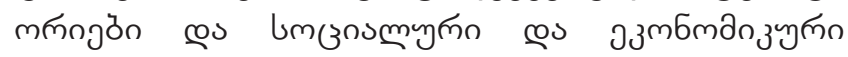

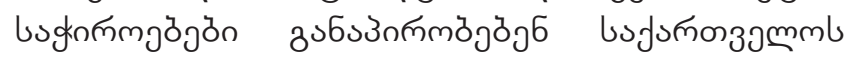

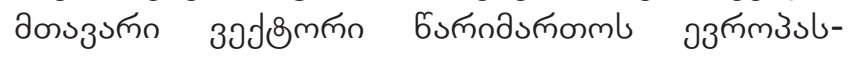

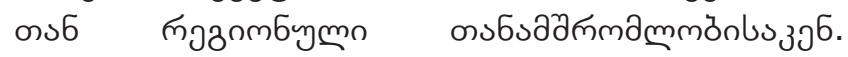

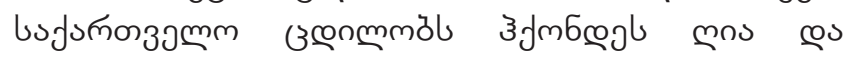

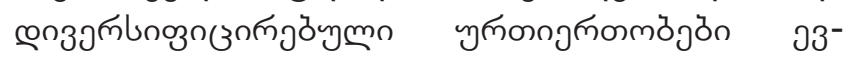

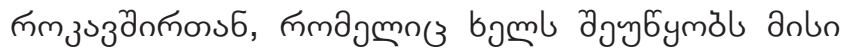

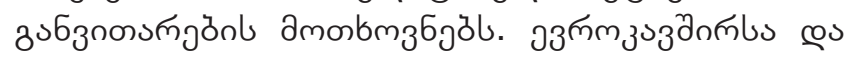

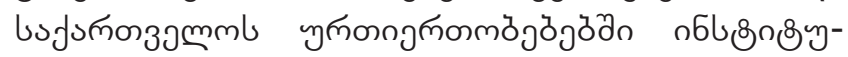

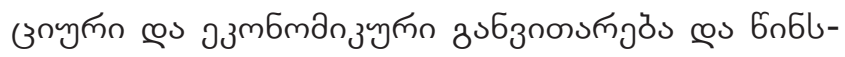

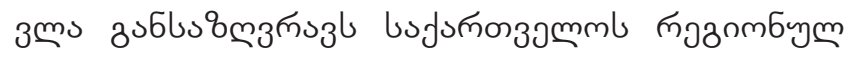

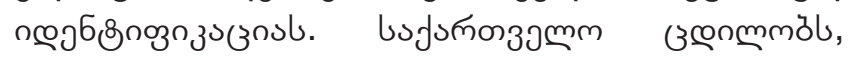

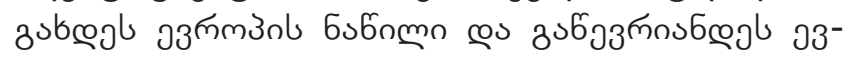

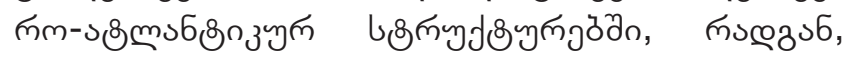

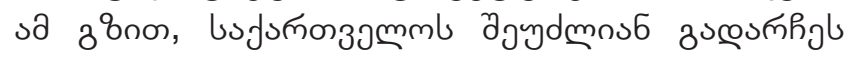

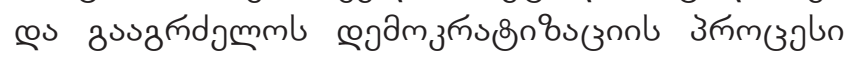

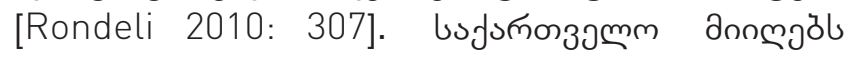
змб зпл

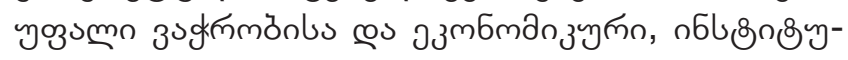

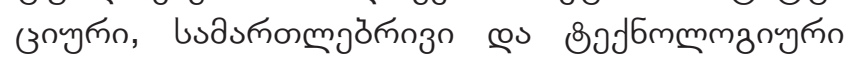

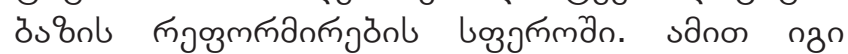

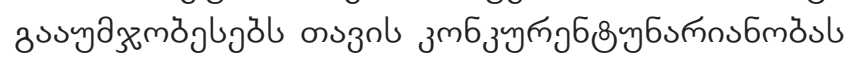

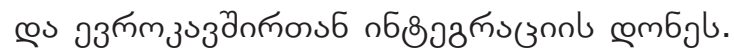

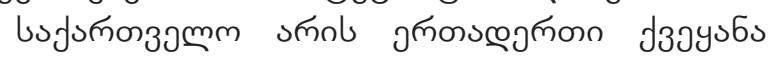
јзп்

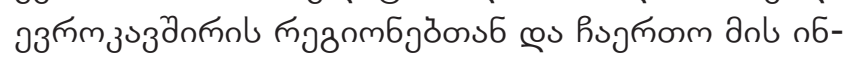

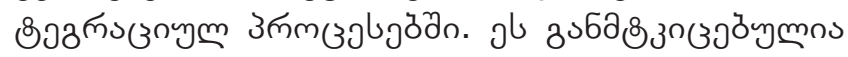
sum(३n一)

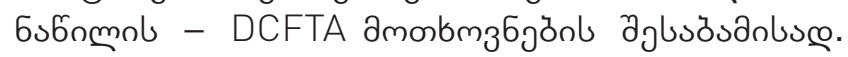

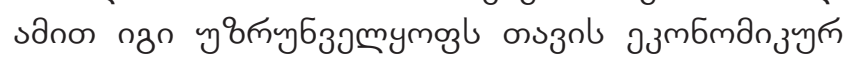

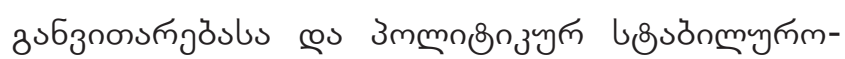
bul.

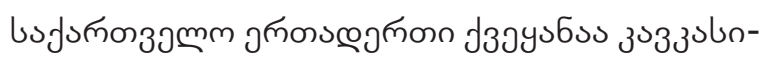

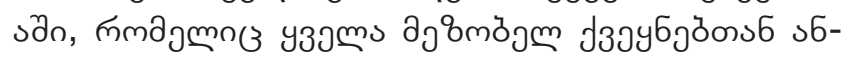

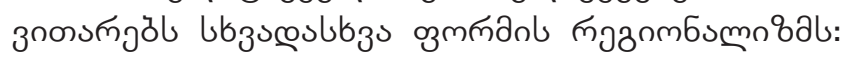

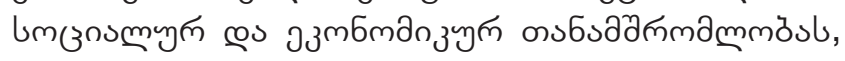

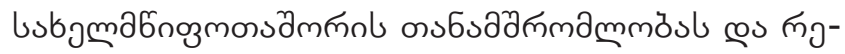

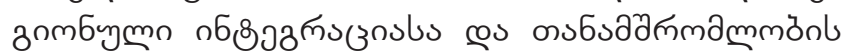
jugmb [Hurrell 1995: 39-45]. bufonon3amml bا

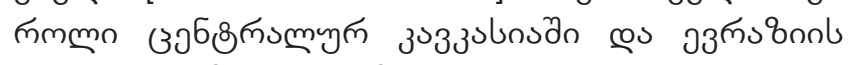

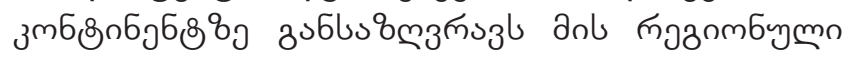

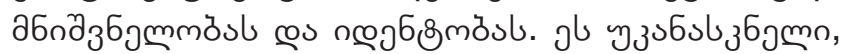

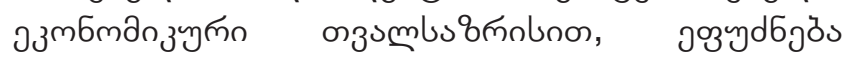

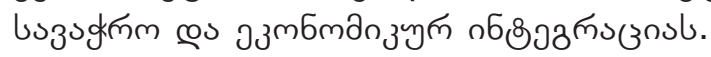

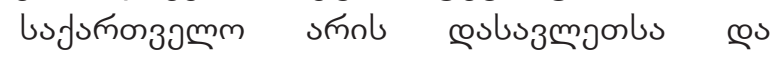

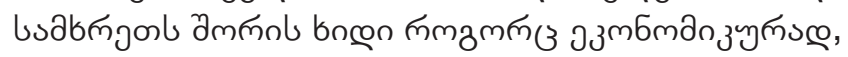

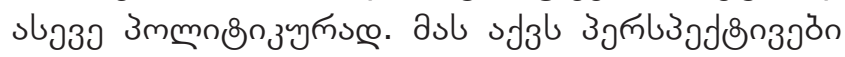

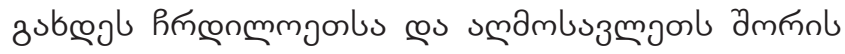

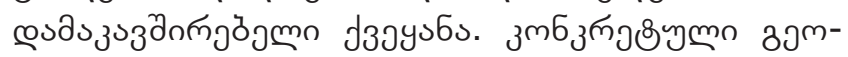

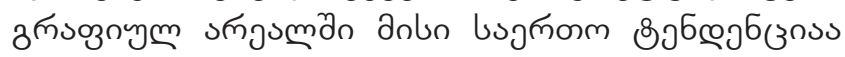

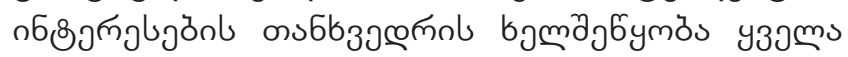

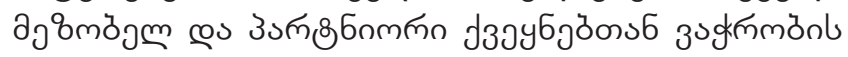

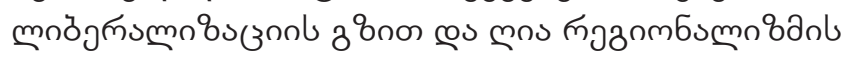

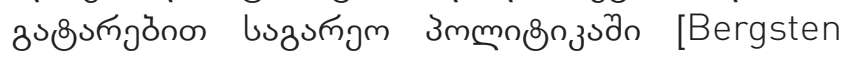

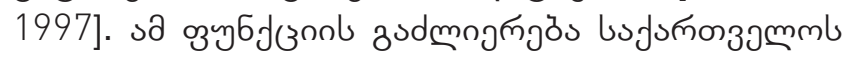

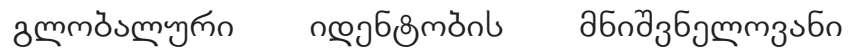

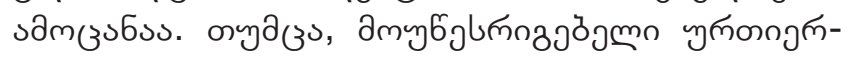

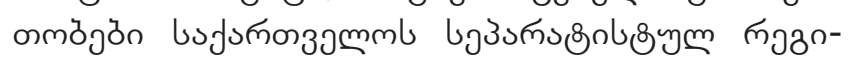

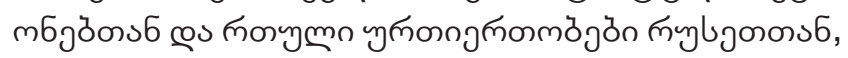

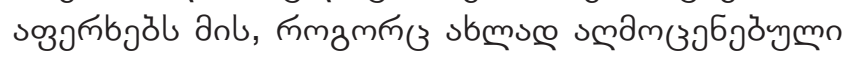

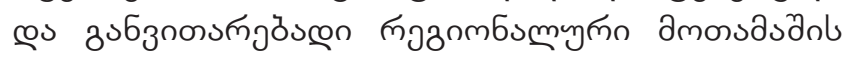
ñmml.

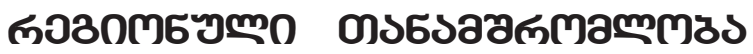

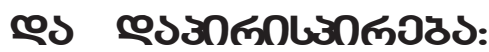

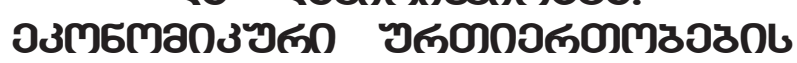

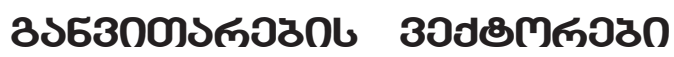

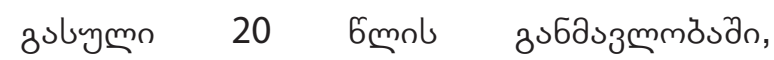

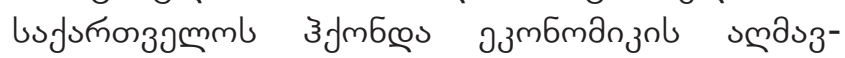

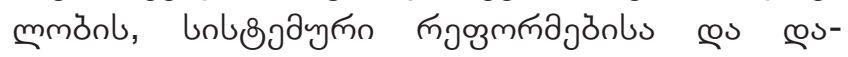

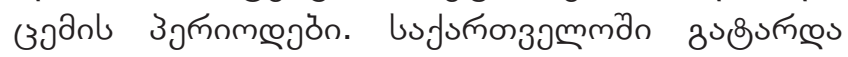

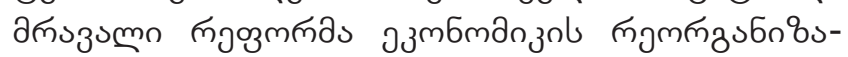

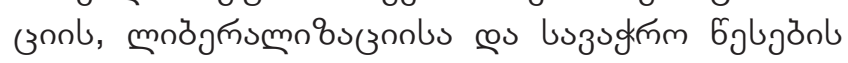

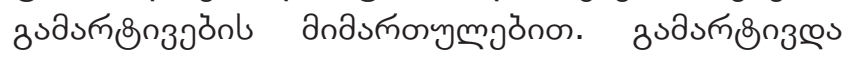

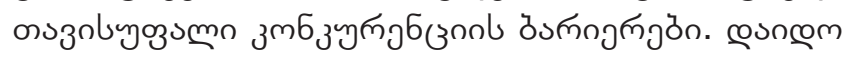

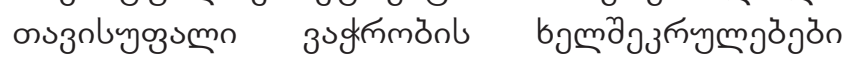

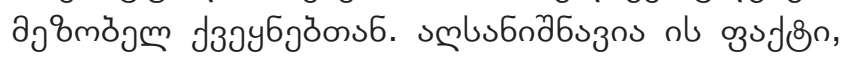

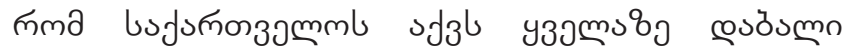




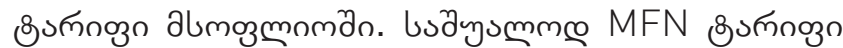
1.4 3имззббвns - ob.: [http://www.wto.org/ english/thewto-e/countries-e/georgia-e.htm].

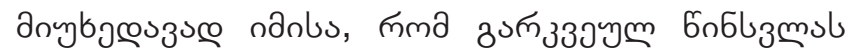

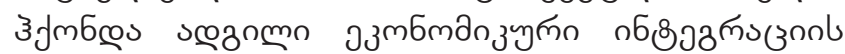

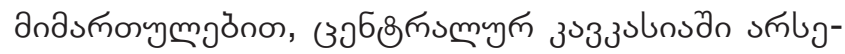

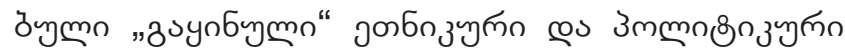

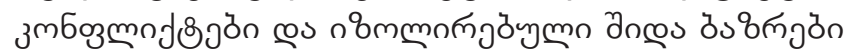

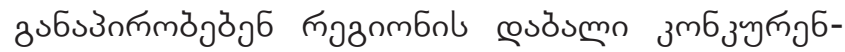
8̈y6unnobmösl [Tokmazishvili 2014].

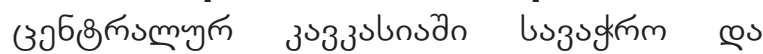

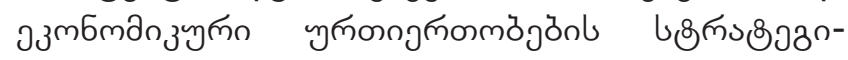

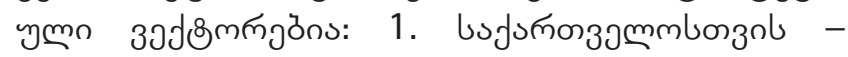

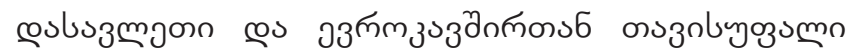

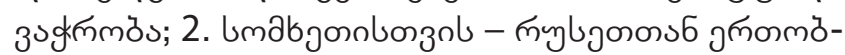

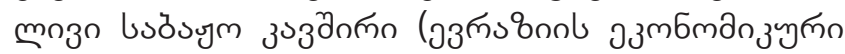

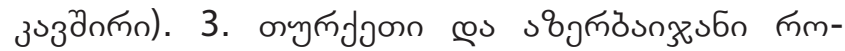

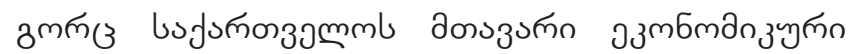
उง sॅrg.

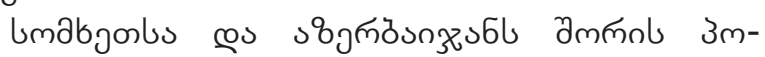

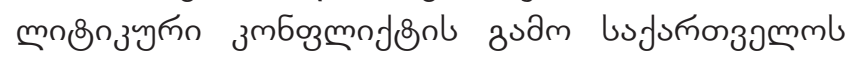

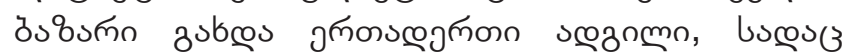

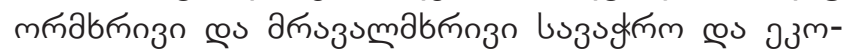

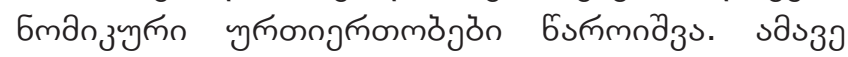

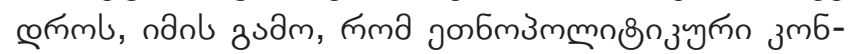

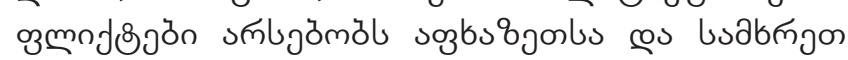

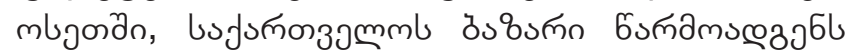

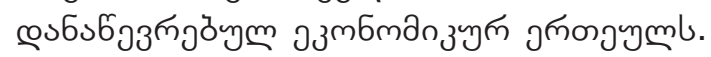

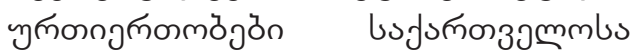

@o s

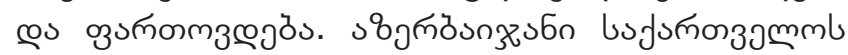

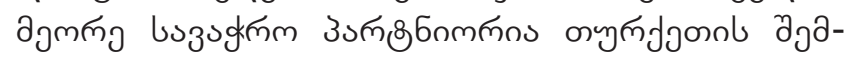
œว3.

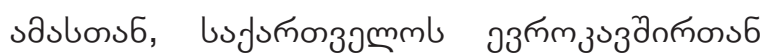

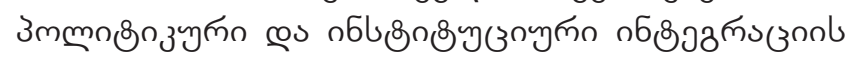

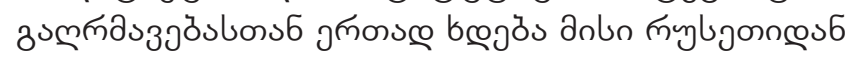

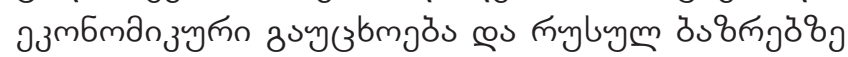

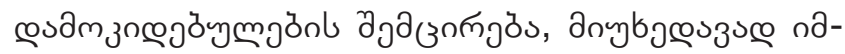

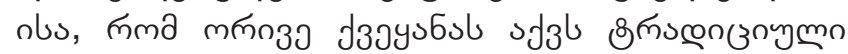

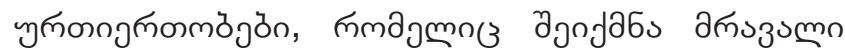

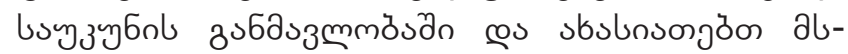

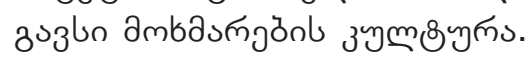

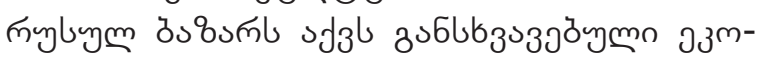

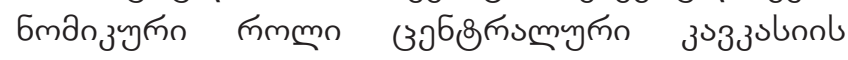

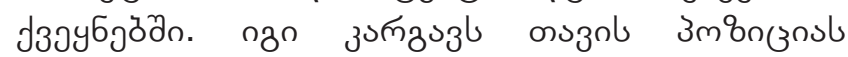

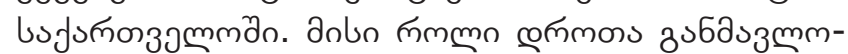

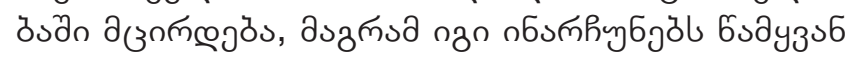

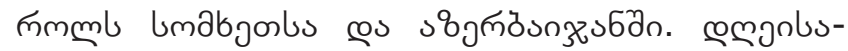

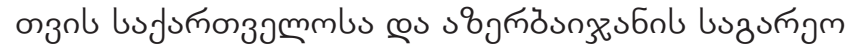

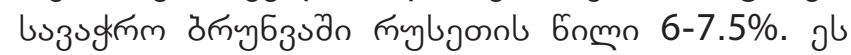

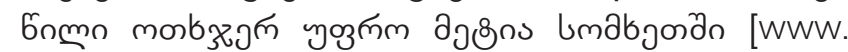
stat.gov.az; www.geostat.ge; www.armstat.arm].

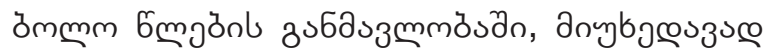

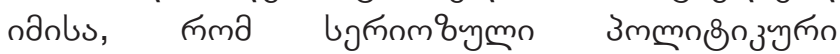

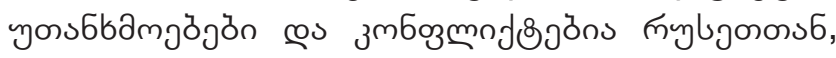

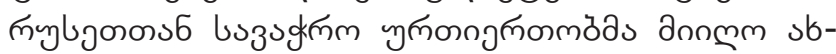

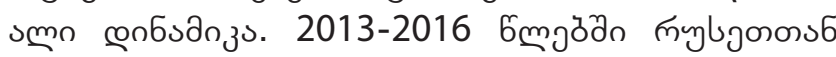

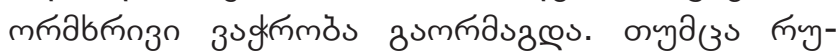

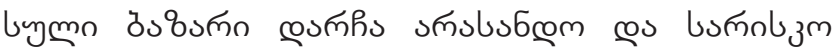
zn86junbonzol.

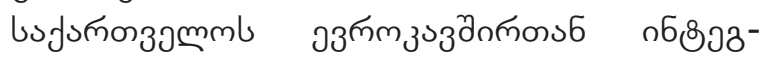

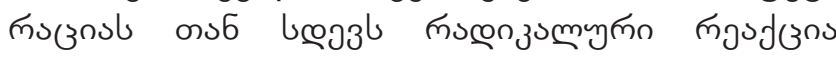

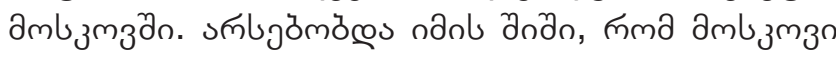

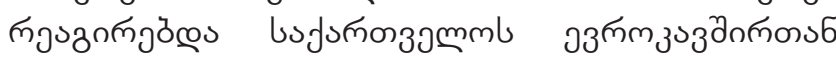

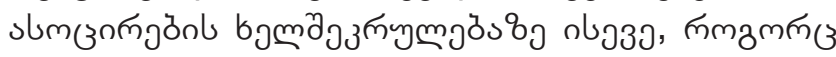

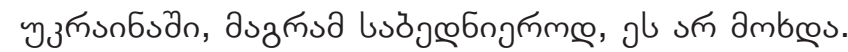

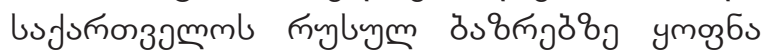

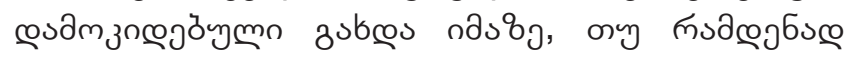

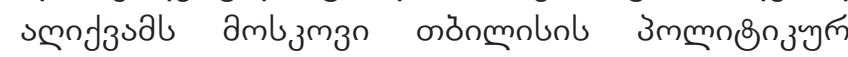

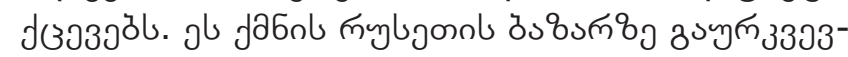

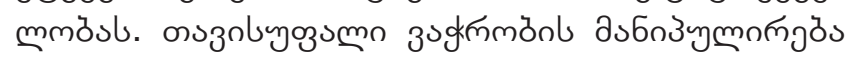

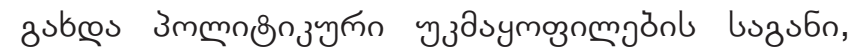

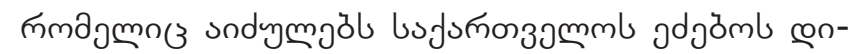

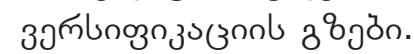

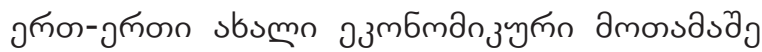

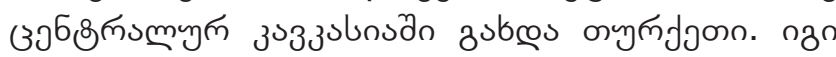

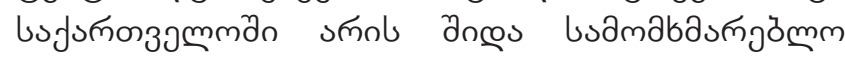

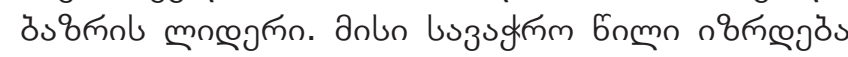

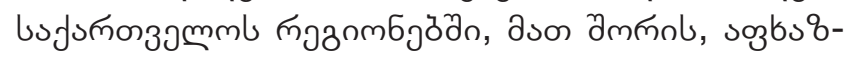

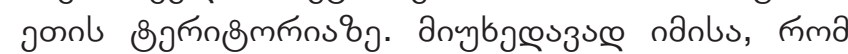

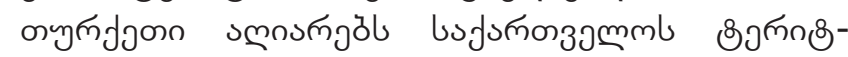

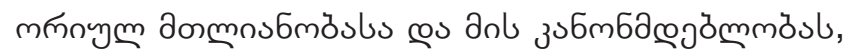

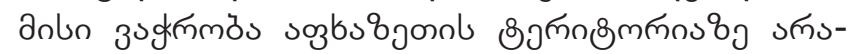

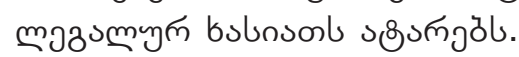

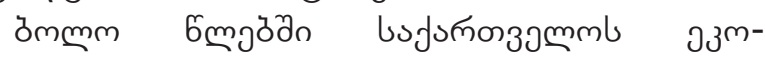

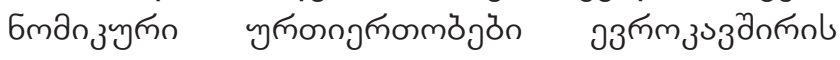

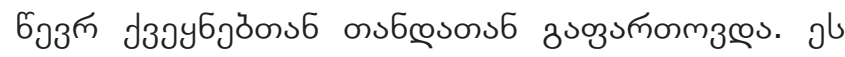

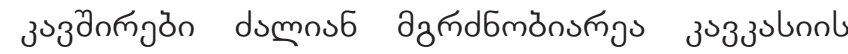

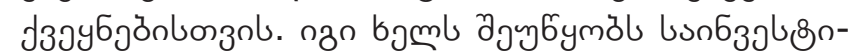

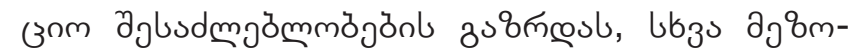

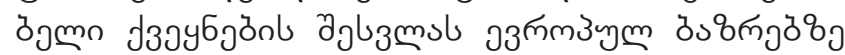

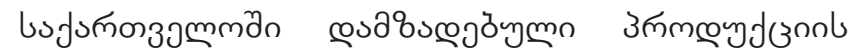

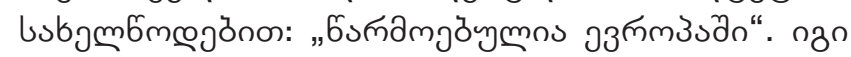

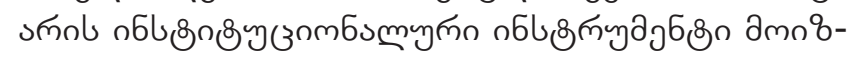
nূmb ubzs јзаy6jön.

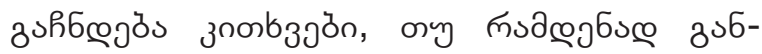

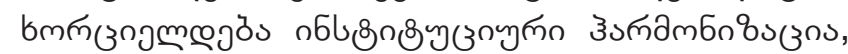




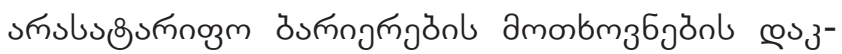

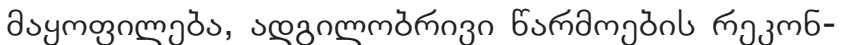

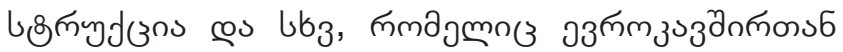

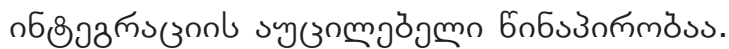

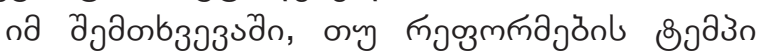

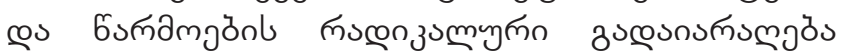

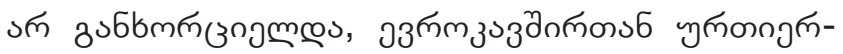
omönl ambummœб

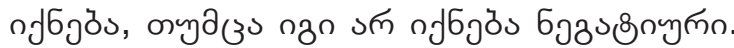

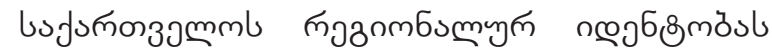

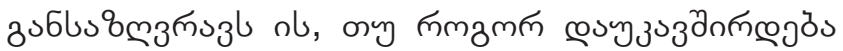

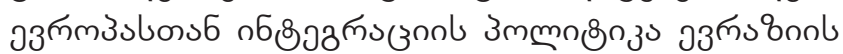

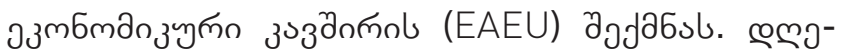

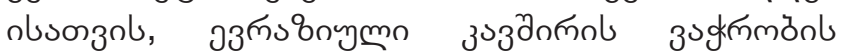

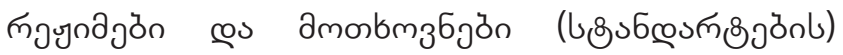

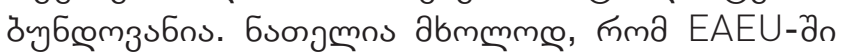
sחা

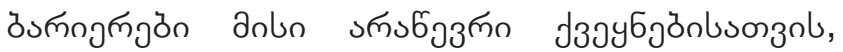

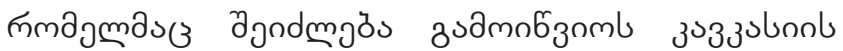

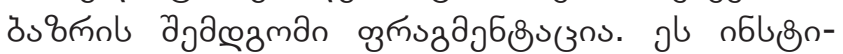

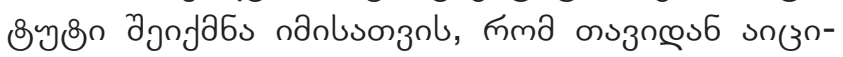

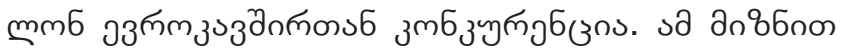

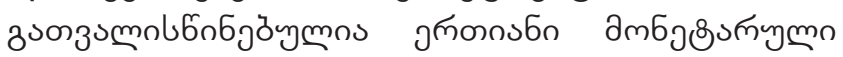

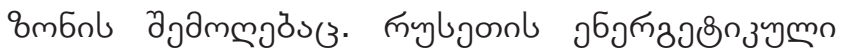

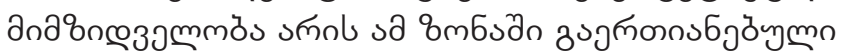

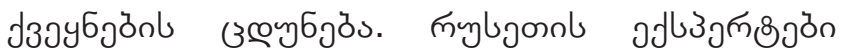

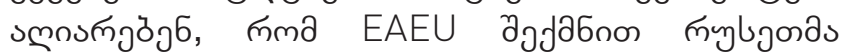

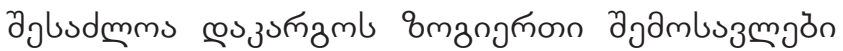

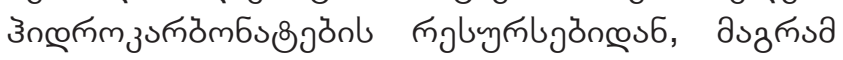

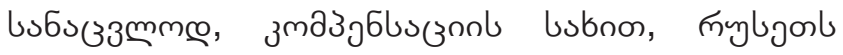

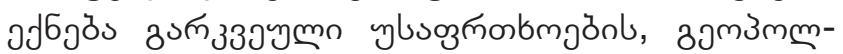

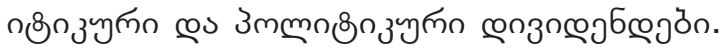

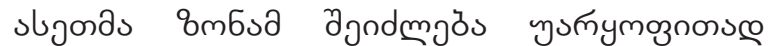

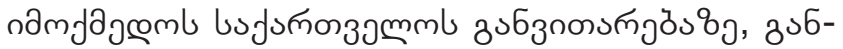
bs zynong

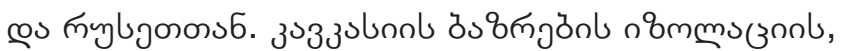

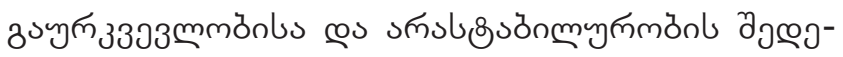

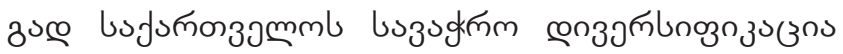

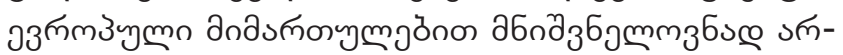
önmgab sbum moluzgl.

səzзйss, пmma DCFTA œs EAEU smols

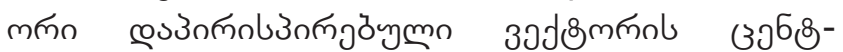

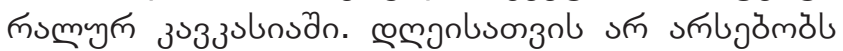

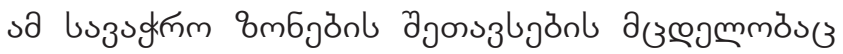
3n.

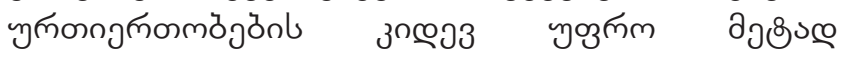

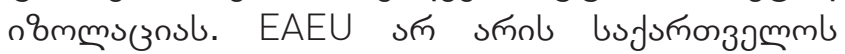

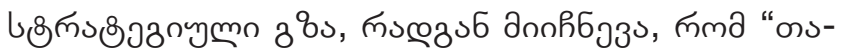

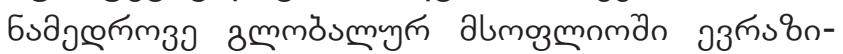

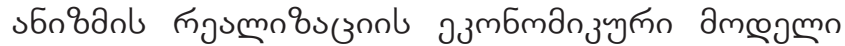
s

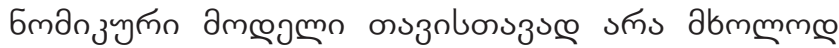

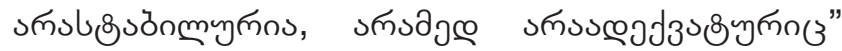
[Papava 2016: 7].

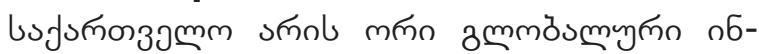

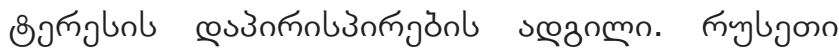

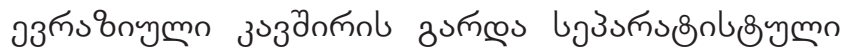

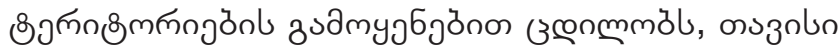

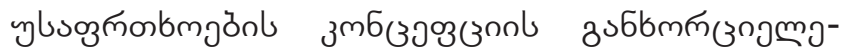

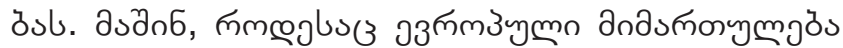

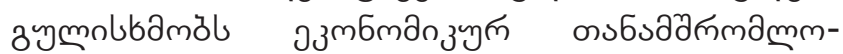

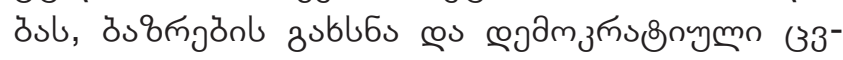

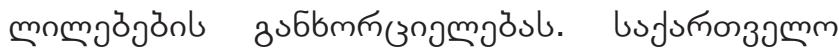

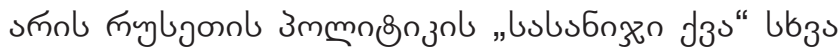

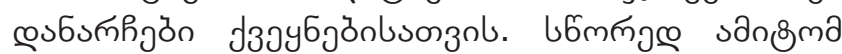

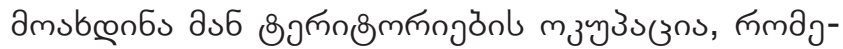

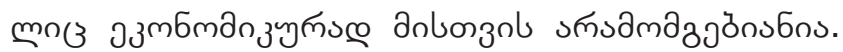

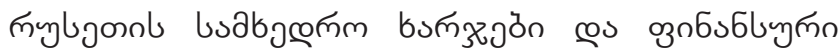

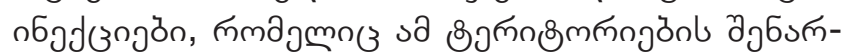

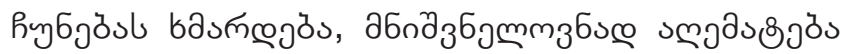

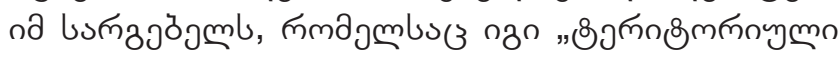

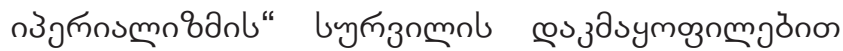

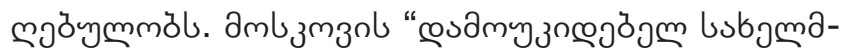

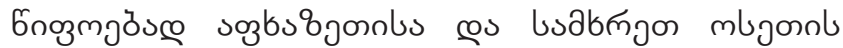

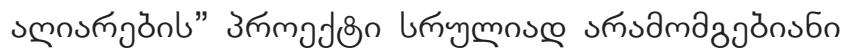

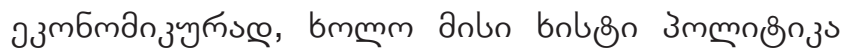

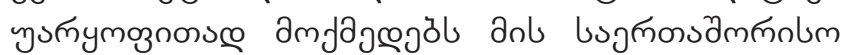
กวกฬชว.

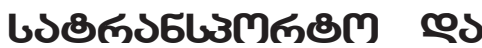

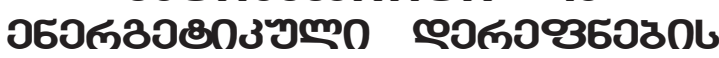

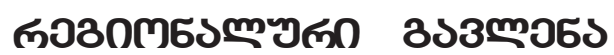

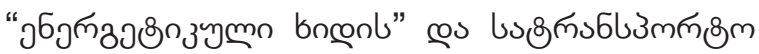

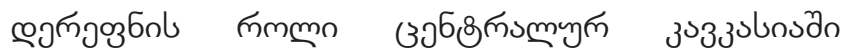

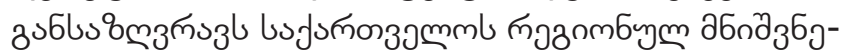

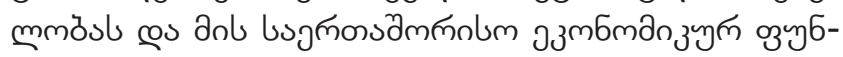

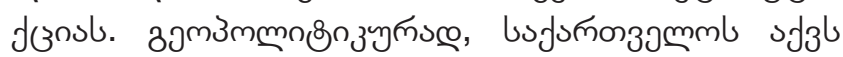

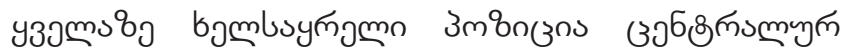

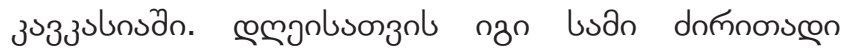

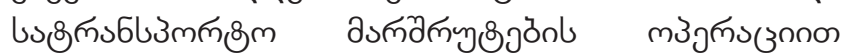

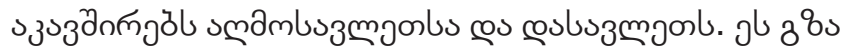

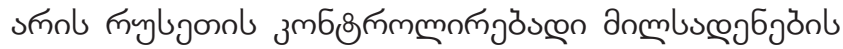

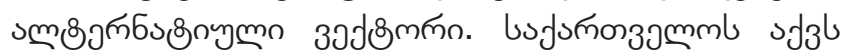

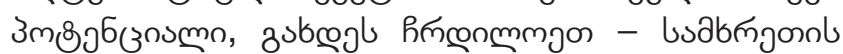

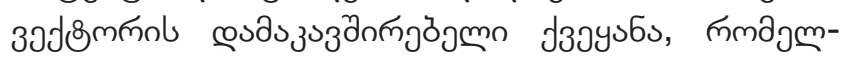

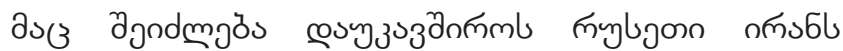

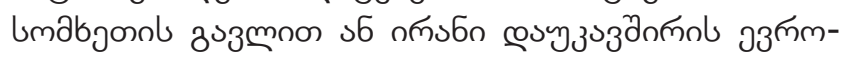

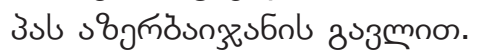




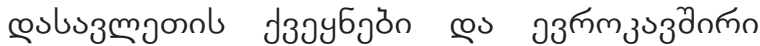

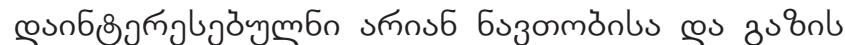

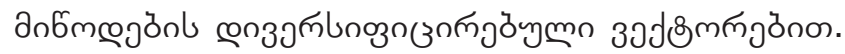

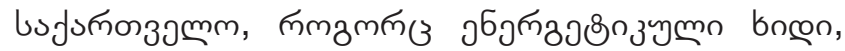

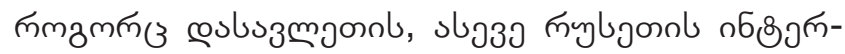

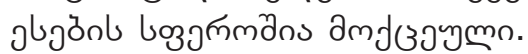

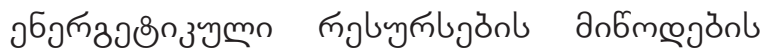

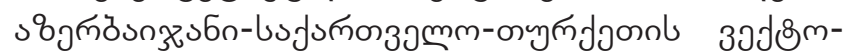

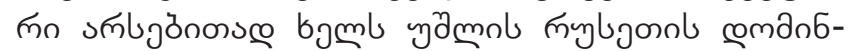

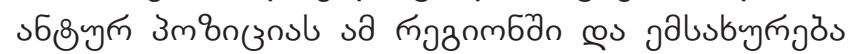

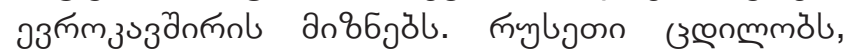

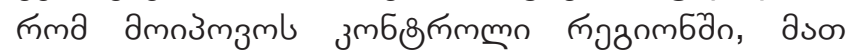
ammol luabjømm dumobbajoznon.

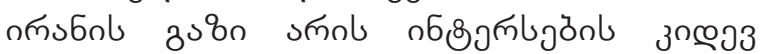

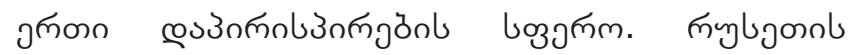

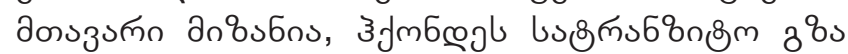

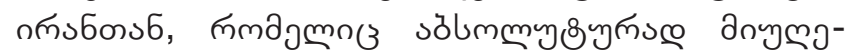

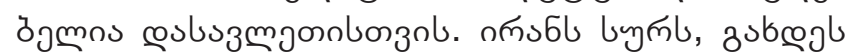

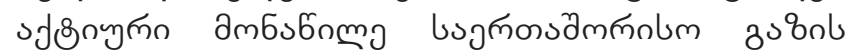

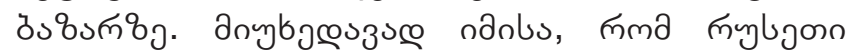

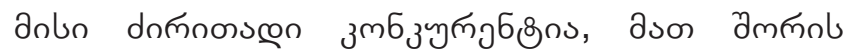

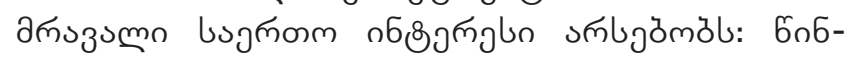

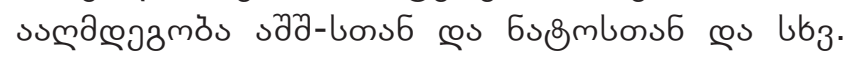

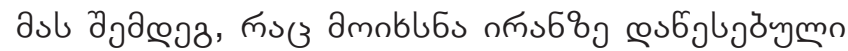

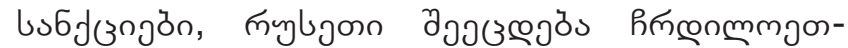

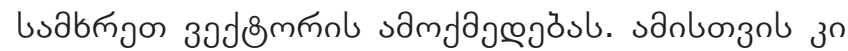

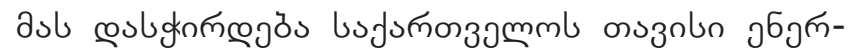

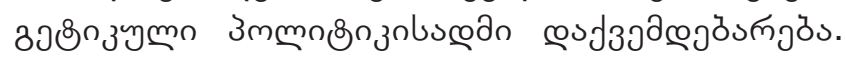

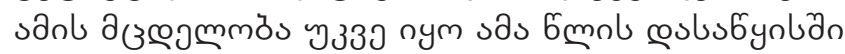

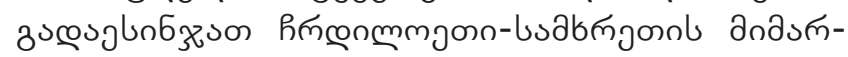

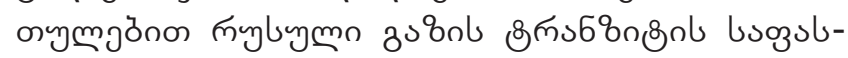

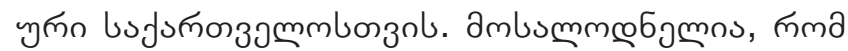

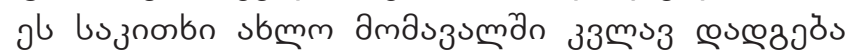

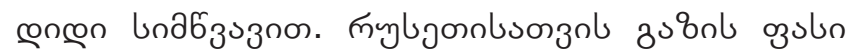

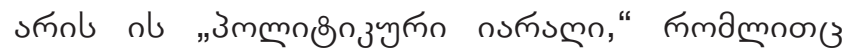

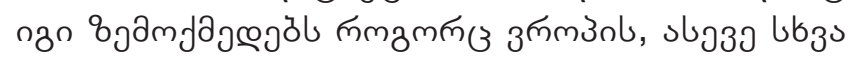

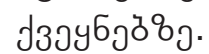

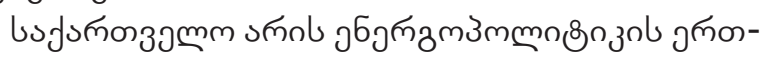

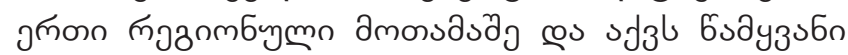

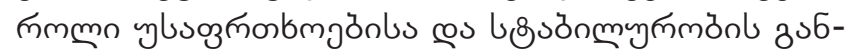

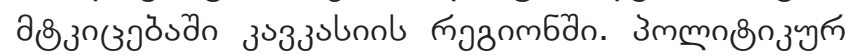

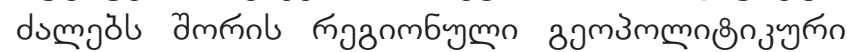

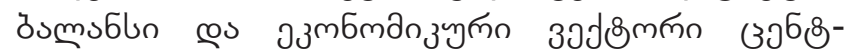

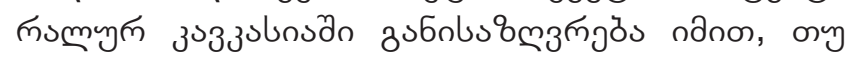
ñ 3m

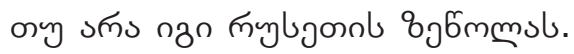

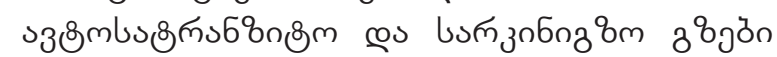

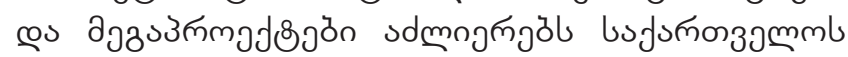

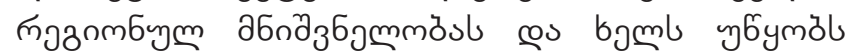

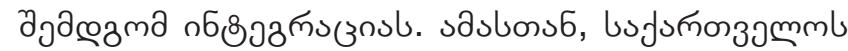

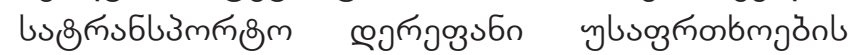

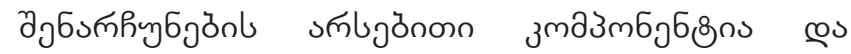

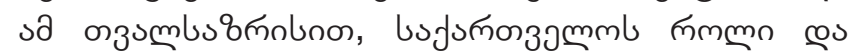

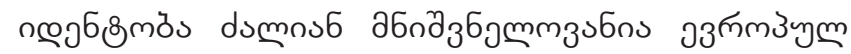

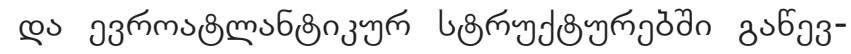

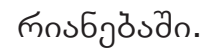

\section{6১}

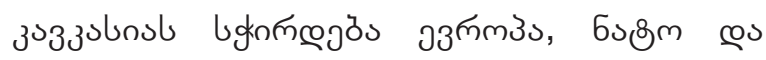

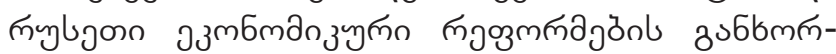

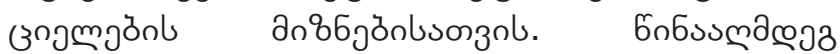

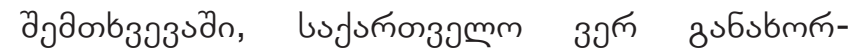

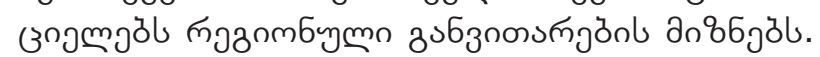

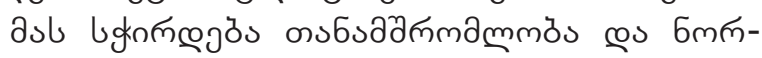

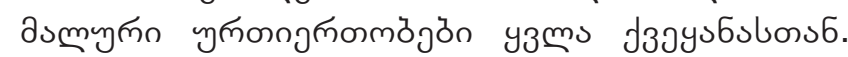

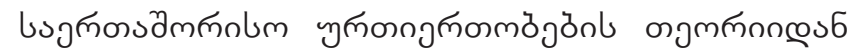

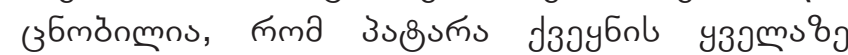

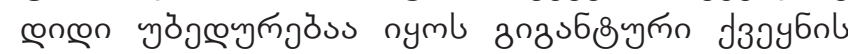

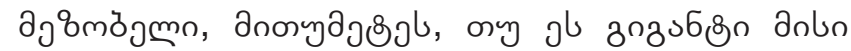

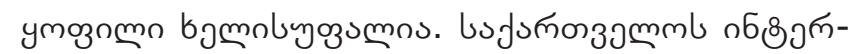

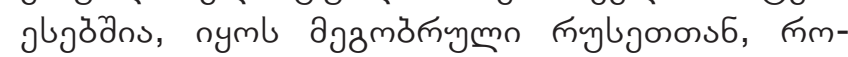

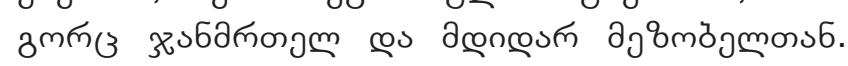
إ

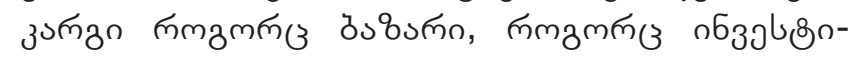

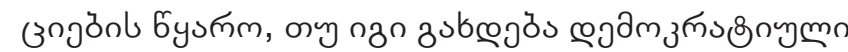

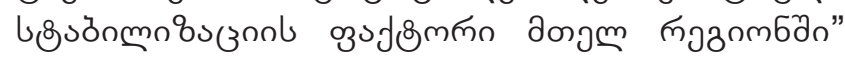

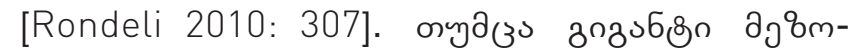

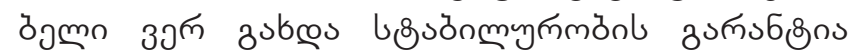

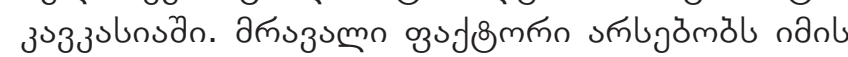

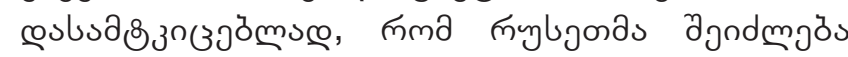

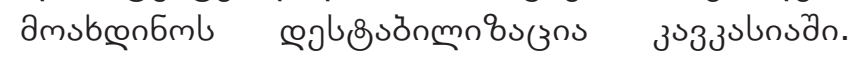

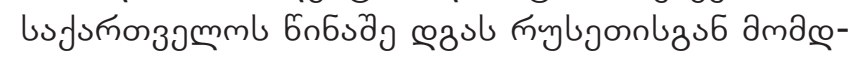

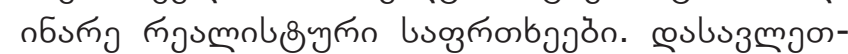

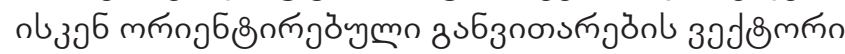

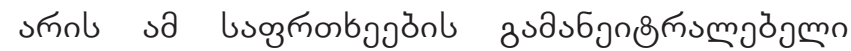

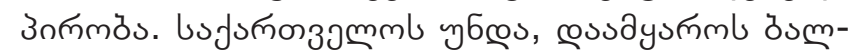

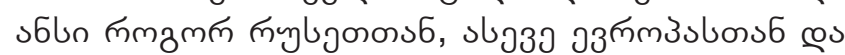

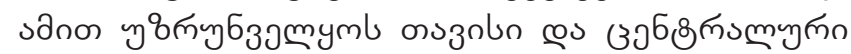

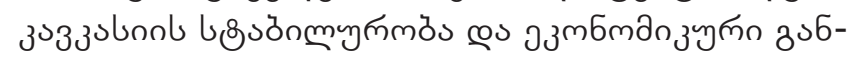
3nonsmgás.

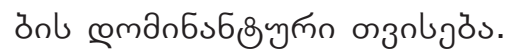




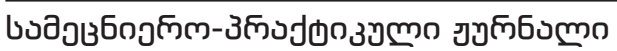

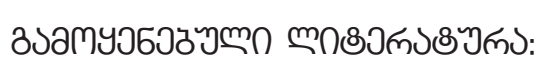

1. Hettne, B. (1996). Globalization, the New Regionalism and East Asia, in the: Globalism and Regionalism, Ed. by Toshiro Tanaka and Takashi Inoguchi. http://archive.unu.edu/unupress/globalism.html.

2. Rondeli, A. (2010). It's Georgia's Interest to be Friendly with Russia. Interview with Dr. Alexander Rondeli. Caucasian Review of International Affairs. VOL. 4 (3). CRIA. http://www.cria-online. org/Journal/12/Done-Interview-with-Alexander-Rondelli.pdf

3. Hurrell, A. (1995). Regionalism in Theoretical Perspective, in Louise Fawcett and Andrew Hurrell (ed.), Regionalismin World Politics.Oxford: Oxford University Press. PP.

4. Bergsten, F. (1997). Open Regionalism, Working Paper 97-3, Peterson Institute for International
Economics. http://www.iie.com/publications/ wp/wp.cfm?ResearchlD=152

5. http://www.wto.org/english/thewto-e/countries-e/georgia-e.htm

6. Tokmazishvili, M. (2014). New Realities in the South Caucasus: Georgia-EC, Armenia-CU: Contradictions and Opportunities for Cooperation. In the book: Russia-Georgia: Challenges and Perspectives in the Economic Sector. ICCN, RIAC. Tbilisi.

7. www.stat.gov.az; www.geostat.ge; www.armstat. arm

8. Papava, V. (2016). Georgia's Choice: The European Union or the Eurasian Economic Union. Georgian Foundation for Strategic and International Studies, Expert Opinion, N 57.

\title{
Political Economy of Regional Identity of Georgia
}

https://doi.org/10.35945/gb.2016.01.006

\author{
Mikheil Tokmazishvili \\ Doctor of Economic Sciences, \\ Professor St. Andrew the First-Called Georgian University \\ of the Patriarchate of Georgia, \\ Ass. Professor Ivane Javakhishvili Tbilisi state University
}

Key words:

GEORGIA, IDENTITY, INTEGRATION

\section{Summary}

Discusses dominant features and characteristics of regional identity of Georgia, characterizes the vectors of development of Central Caucasian counties and role of Georgia in regional cooperation, assessed the impact of the foreign trade and conflict between the EU and the Eurasian Union and determined the geopolitical function of Georgia in the Central Caucasus. 